DOI: https://doi.org/10.17648/2238-037X-trabedu-v29n1-20987

(c) (1) https://creativecommons.org/licenses/by/4.0/

\title{
EDITORIAL
}

\section{TRABALHo \& EducAÇÃo EM tempos de PANDEMIA E CRISE do}

\section{CAPITAL}

A presente edição da revista Trabalho \& Educação, v. 29, n. 1 (2020), chega em um trágico momento da história contemporânea e, particularmente, do nosso país. Ainda não é possível estimar o número de óbitos que decorrerão da pandemia do novo coronavírus (Covid-19), mas já se percebe brutalmente como ela agrava outras crises que já estavam em curso, a exemplo das crises econômica e social. O caráter eminentemente global destas evidencia a complexidade do sistema capitalista e sua dependência da exploração da força de trabalho e geração de mais valia para sustentar o ritmo da acumulação de capital. Diante da maior calamidade sanitária e da mais grave crise econômica de nossa época, a previsão é de recessão e queda na produção mundial em torno de 3\% neste ano (FMl, 2020) e fechamento de milhões de postos de trabalho. No caso do nosso país, a previsão do Relatório de Mercado, publicado pelo Banco Central em 22 de maio de 2020, é de uma queda de 5,89\% do PIB brasileiro, a maior já registrada na história do Brasil (BC, 2020).

No Brasil, em um momento de urgência histórica da ação efetiva do Estado para enfrentamento da epidemia por meio de investimentos em saúde pública, incentivo ao isolamento social e provisão de garantias de condições mínimas para sobrevivência da grande massa vulnerabilizada, a política econômica dos Chicago Oldies ${ }^{1}$, a passos lentos, concede o coronavoucher ${ }^{2}$ à parte da população até o momento não alcançada pelas ações governamentais. As insuficientes e desorientadas políticas governamentais atuam no sentido de favorecer o setor privado e o financeiro ${ }^{3}$, enquanto assistimos a agudização da pobreza e o alargamento do fosso social.

As ações políticas conduzidas pelo governo federal brasileiro e pelo governo estadual de Minas Gerais esgarçam ainda mais nosso frágil tecido social, fomentando a expansão de desigualdades econômicas, exclusões sociais e crimes ambientais. Em um contexto de pandemia, as desigualdades se tornam mais evidentes e expõem o fato de que

\footnotetext{
1 Termo empregado para fazer referência aos integrantes da equipe econômica do governo Bolsonaro (a exemplo do próprio Ministro da Economia Paulo Guedes) que se formaram há algumas décadas na Universidade de Chicago (EUA), escola fortemente alinhada ao pensamento econômico liberal. Tal alcunha também lembra a expressão utilizada para se fazer menção a um grupo de economistas chilenos que também tiveram formação acadêmica na mesma Escola e formularam as políticas econômicas da ditadura do general Pinochet no Chile.

2 Coronavoucher ou auxílio emergencial é o benefício instituído pela Lei 13.982/2020 aos trabalhadores informais e de baixa renda tendo em vista a mitigação dos impactos sociais e econômicos decorrentes das condições impostas pela pandemia do Covid-19.

${ }^{3}$ A exemplo da Medida Provisória № 936/2020 (permite a redução de carga horária atrelada à redução de salários dos trabalhadores - públicos e privados - sem a participação dos sindicatos nas negociações) e da Emenda Constitucional nํ 106 de 07 de maio de 2020 (institui regime extraordinário fiscal, financeiro e de contratações para enfrentamento da calamidade pública decorrente de pandemia).
} 
grande parte da população brasileira não tem acesso às condições mínimas de higiene e possibilidades de se isolar em casa. Esta é a realidade de muitos que vivem em vilas e favelas, daqueles que estão em situação de rua, da população carcerária brasileira, bem como dos que seguem em trabalhos precários, sejam eles essenciais ou não. Neste sentido, verifica-se que a pandemia carrega um recorte de classe, gênero e raça.

Não bastasse essa dura realidade brasileira, a pandemia do novo coronavírus nos atinge num momento em que, mundialmente, $\mathrm{o}$ irracionalismo, $\mathrm{o}$ neopragmatismo, 0 negacionismo e o fundamentalismo dominam, cada vez mais, os espaços da vida. Essa preocupante constatação nos traz à mente os mais sinistros momentos já vivenciados na história humana.

Nesse cenário, o conhecimento científico, que poderia apontar possíveis caminhos para minorar nossas agruras, é renegado por necropolíticas (MBEMBE, 2018) responsáveis por agravar os infortúnios que nos assolam, em meio a ondas de desinformações que inundam a internet $e$ as redes sociais online. As tecnologias de informação e comunicação, que poderiam constituir instrumentos para atenuar nossas atuais desventuras, são cada vez mais empregadas para estabelecer um poder informacional (BRAMAN, 2006) que está a serviço de grupos que assumem abertamente identidades fascistas e aliam-se a hostes de milicianos facínoras e corruptos.

Diante da suspensão temporária da educação presencial, imposta pela necessidade de desacelerar a propagação do COVID-19, as instituições de ensino privadas vêm na Educação a Distância (EaD) um instrumento para manter o mercado educacional em operação, preservar taxas de retorno de investimento, índices de lucratividade e payback. Para as classes menos favorecidas da sociedade, o resultado não poderia ser pior. Grande parte da população brasileira não possui os instrumentos tecnológicos mínimos e acesso à Internet com a qualidade necessária para participar efetivamente das dinâmicas pedagógicas não presenciais. Além disso, boa parte das instituições de ensino denominadas "públicas", financiadas pelo Estado, não possuem recursos financeiros, tecnológicos e humanos para migrar o ensino para o ambiente digital. Assim, ampliam-se antigas desigualdades socioeducativas, num evidente favorecimento das classes mais abastadas da sociedade brasileira.

Nesse angustiante cenário, a equipe editorial da revista Trabalho \& Educação seguiu suas atividades por meio do trabalho remoto e reuniões via internet. Privados dos nossos saudáveis encontros presenciais, enfrentamos o desafio de manter a regularidade da revista em meio a esse turbilhão que nos tragou. Para suplantar as dificuldades editoriais, alguns elementos nos motivaram e alimentaram nosso desejo de superação. Em primeiro lugar, o desejo de contribuir com a produção e a difusão de conhecimentos científicos que tenham como horizonte a perspectiva emancipatória. Em segundo lugar, o compromisso com a própria revista, importante veículo a serviço da educação, da produção e divulgação de saberes. Ademais, o respeito com autores e autoras que nos confiaram seus trabalhos acadêmicos e resultados de pesquisas. E finalmente, mas não menos importante, o desejo de manter nossos leitores atualizados em relação às produções acadêmicas do campo Trabalho e Educação comprometidas com o pensamento crítico. O resultado desse esforço coletivo é o que nossos leitores e leitoras podem agora conhecer.

Em primeiro lugar, merece destaque nesta edição, a entrevista que o Professor Luís ALCOFORADO concedeu para Carlos COSTA e José G. OLIVEIRA. Alcoforado é professor da Faculdade de Psicologia e de Ciências da Educação da Universidade de 
Coimbra, onde coordena o Mestrado em Educação e Formação de Adultos e Intervenção Comunitária. Os entrevistadores conduzem o entrevistado a discorrer sobre instigantes temáticas que incluem, por exemplo, a educação continuada e o aprendizado da vida; os primórdios do pensamento pedagógico contemporâneo; o surgimento e a evolução das universidades europeias; os desafios futuros a serem enfrentados pelas universidades; o trabalho na era pós-industrial, também chamada de era da indústria 4.0; as contribuições de Walter Benjamin, Luc Ferry e Paulo Freire para essas questões; as relações entre universidade e mercado; dentre outros temas.

Abrindo a seção de artigos, Leonardo Moura Lima Calmon de SIQUEIRA e Laura Neves de SOUZA questionam a proposta, publicada em 2018 pelo Banco Mundial, de investimento em capital humano como uma solução para o desemprego estrutural decorrente da adoção das novas tecnologias da robótica e da inteligência artificial. Para atingir esse objetivo, os autores tomam por base: (1) a análise da inserção dos trabalhadores brasileiros no mercado de trabalho do país, a partir da perspectiva das credenciais educacionais destes trabalhadores, por meio dos dados do IBGE na Pesquisa Nacional por Amostra de Domicílios (PNAD) para o período de 2001 a 2015; (2) os impactos sobre o trabalho que decorrem da adoção das novas tecnologias; (3) as transformações atuais do mundo do trabalho e os desafios decorrentes das metamorfoses vivenciadas pela classe-que-vive-do-trabalho. $O$ artigo conclui ser oportuna a reflexão sobre uma alternativa de política pública educacional que tenha por propósito o desenvolvimento de uma compreensão crítica da sociedade brasileira, levando em consideração não apenas a formação para o trabalho, mas, também para a atuação social e política.

O artigo apresentado por Julierme Antônio dos SANTOS e Bruna Tarcília FERRAZ ressalta o papel político do educador como sujeito que deve contribuir para a formação crítica dos cidadãos e discute a importância do fortalecimento da identidade docente a partir do acesso a uma educação de qualidade. O ponto central do artigo está em discutir o papel da formação continuada de professores para o Ensino Médio, bem como avaliar, por meio de pesquisa qualitativa junto aos professores orientadores de estudo, as contribuições vivenciadas com o Programa Nacional de Fortalecimento do Ensino Médio (PNEM). Os autores destacam a importância da continuidade nos processos de formação docente como elemento que fomenta a reflexividade crítica e contribui para o conjunto da categoria na luta por melhores condições para a educação.

Alexsandra Joelma Dal Pizzol COELHO e Nilson Marcos Dias GARCIA investigaram as motivações que levaram a permanência ou abandono dos estudantes trabalhadores de uma Instituição Federal com campi em Joinville e Jaraguá do Sul (Santa Catarina/ PR) na Educação Profissional. Com base na concepção de trabalho como categoria central e princípio educativo, COELHO e GARCIA dialogaram com autores de diferentes correntes teóricas contribuindo para enriquecer a discussão em torno da questão em tela. Desde a perspectiva de que a permanência e o abandono escolar envolvem muitos fatores, a pesquisa, de caráter qualitativo, buscou contemplar os seguintes aspectos: (1) Fatores internos - compreensão dos motivadores institucionais para permanência ou abandono; (2) Fatores externos - questões sociais, econômicos e culturais para tais motivadores; (3) Fatores pedagógicos - internos e externos na relação ensino aprendizagem; e (4) Políticas públicas e ações de apoio à permanência - buscando avaliar a compreensão dos estudantes sobre as mesmas. 
Elisabete CORCETTI e Maria das Dores Saraiva de LORETO apresentam o resultado de pesquisa de doutorado que investigou as políticas públicas de validação e reconhecimento de aprendizagens informais e não formais em Portugal e também no Brasil. O artigo objetiva verificar as lógicas, os pressupostos e as crenças no contexto do desenho das políticas públicas de educação e formação de adultos em Portugal, a partir do ano de 2015. A pesquisa, qualitativa e transdisciplinar, estabelece um diálogo entre os princípios epistemológicos dos estudos discursivos críticos com a pedagogia crítica. Nos termos das autoras, os resultados da análise revelam que "o discurso do Programa Qualifica prioriza a continuidade dos estudos em setores e ambientes formais, em detrimento da valorização de aprendizagens nos setores informais e não formais, mantendo a finalidade de gestão de recursos humanos, em uma lógica de preparação de mão de obra, direcionada para as demandas do mercado de trabalho".

A partir de resultados de tese de doutorado defendida junto à Faculdade de Educação da Universidade Estadual de Campinas (FE/Unicamp), Dalvane ALTHAUS versa sobre a experiência de uma pedagoga que entra em contato a abordagem teóricometodológica denominada Clínica da Atividade (CA), ligada a psicologia do trabalho. Criada por Yves Clot (2010) e seus colaboradores, esta almeja, por meio de um movimento psicológico-dialógico de auto-observação, promover mudanças nas situações de trabalho, que têm o professor como protagonista de sua prática e 0 pedagogo como organizador do processo. Levado a se observar em sua atividade e por meio de um diálogo com outros e consigo mesmo, o professor passa a se perceber naquela ação e a compreender de que maneira poderá se transformar. Ao longo do texto, a autora expõe a trajetória da pedagoga em questão, seu encontro com a nova abordagem pedagógica da CA, bem como apresenta algumas especificidades desta juntamente com uma amostra de intervenção e sua breve análise, tecendo por fim, suas considerações.

O artigo de Elvira Cristina Martins TASSONI e Bruna Aparecida Alves ALMEIDA traz resultados de uma pesquisa que investigou a produção acadêmica dos grupos de pesquisas certificados pelo CNPq que têm como foco a formação de professores. As autoras inventariaram as produções desses grupos entre os anos de 2012 a 2015, o que permitiu mapear as tendências que têm impulsionado as pesquisas científicas no campo da formação de professores, delineando o movimento da área. Essas tendências foram organizadas em quatro núcleos temáticos que evidenciam as interfaces da formação de professores com os saberes docentes e práticas pedagógicas; com as políticas educacionais; a formação de professores nas diferentes etapas e modalidades de ensino; e a formação inicial e continuada.

Amanda Cristina Ferreira MARINHO, Suzi Maria Nunes CORDEIRO e Helaine Patrícia FERREIRA nos apresentam suas reflexões acerca do conhecimento de educadores da Teoria Histórico-Cultural elaborada por Lev Semionovich Vygotsky (1896-1934), verificando a aplicabilidade dessa teoria na prática docente. $O$ artigo é resultante de uma pesquisa de caráter qualitativo, realizada junto a sete professores da rede municipal de ensino do Estado do Paraná, através de questionário semiestruturado e sociodemográfico. A investigação teve como o objetivo principal identificar as representações sociais de professoras que atuam nos anos iniciais do ensino fundamental na rede municipal de ensino do Estado do Paraná sobre a teoria vygotskyana, de modo a compreender como estas representações repercutem (ou não) na ação pedagógica. Os dados analisados à luz da Teoria das Representações Sociais levaram as autoras à hipótese de que há uma dicotomia entre a teoria e a prática na 
formação dos professores, fazendo com que o entendimento que possuem acerca da Teoria Histórico-Cultural não seja aplicado à prática docente. $\mathrm{O}$ artigo retoma ainda a importância de Vygotsky para a educação.

O trabalho de Álvaro Bubola POSSATO e Patrícia Ortiz MONTEIRO analisa o modo como os docentes do ensino profissionalizante fazem uso de ferramentas de tecnologia de informação e comunicação com vistas à entender como o uso destas tecnologias podem impactar positivamente a atividade profissional desses docentes, melhorando seu desempenho e fornecendo subsídios para sua prática. $\mathrm{O}$ artigo, fruto de pesquisa descritiva e exploratória realizada com 16 professores do Vale da Paraíba/SP, aponta desafios que os docentes de tecnologia da informação e comunicação enfrentam ao lidar com a tecnologia, bem como a necessidade e importância das mesmas em suas práticas.

A categoria política na obra do filósofo húngaro György Lukács é o eixo norteador das reflexões que Daniel Handan TRIGINELLI e Sara Tatiane de JESUS nos apresentam em seu artigo. Os autores colocam em relevo e discutem a categoria política em relação ao desenvolvimento histórico humano. Daniel e Sara buscam atualizar a compreensão e a influência que ela apresenta no desenvolvimento do ser social em seu processo contínuo de reprodução. No mesmo sentido, os autores problematizam os efeitos dos desdobramentos que a categoria política promove no momento histórico contemporâneo, quando a humanidade se encontra diante da hegemonia da ordem do capital. Nesse percurso, o artigo emprega não somente as lentes de Karl Marx e György Lukács, mas também as contribuições de alguns de seus intérpretes, como Ester Vaisman, Hormindo Pereira de Souza Junior e Ronaldo Vielmi Fortes.

Gênero e as relações sociais de sexo no bojo dos debates acerca da organização e divisão do trabalho são os temas tratados por Lucimara MOREIRA e Raquel QUIRINO. $\mathrm{O}$ artigo traz um debate contemporâneo de grande relevância e necessidade para compreensão da sociedade atual, levando em conta suas construções sociais e os impactos destas na criação e manutenção de desigualdades, entre elas, a de gênero. Partido principalmente dos estudos de Smith, Durkheim, Marx e Engels sobre a temática da divisão do trabalho, e recorrendo às obras de Kergoat e Hirata sobre divisão sexual do trabalho e relações sociais de sexo, as autoras demostram de forma crítica e aprofundada, como a divisão sexual do trabalho contribui com a desvalorização social e econômica das mulheres que, embora sejam um percentual significativo no mercado de trabalho, ainda são socialmente e economicamente desvalorizadas e inferiorizadas em relação aos homens. $\mathrm{O}$ artigo aborda a sobrecarga de trabalho comumente enfrentada pelas e mulheres e ainda, a relevância dos estudos feministas no que tange à importância de se reconhecer a dimensão sexual dos sujeitos situados no tempo e espaço, para uma melhor compreensão acerca do trabalho e suas dinâmicas.

Iniciando a sessão de resumos de teses e dissertações, Flávia Assis ALVES apresenta sua dissertação de mestrado profissional (FaE/UFMG), cuja pesquisa teve como centralidade as narrativas das(os) trabalhadoras(es) nas experiências de trabalhos coletivos, dentro dos princípios da economia solidária. A autora objetivou a compreensão do processo de participação social das pessoas que vivem da proposta da economia solidária para a constituição de sujeitos políticos, bem como propôs revelar o sentido do trabalho associado para a vida destes sujeitos e como estes lidam com as contradições impostas pelo modo de produção capitalista. Agradecemos a autora pela concessão da 
imagem, fruto de sua pesquisa, para a capa desta edição da revista Trabalho \& Educação.

O empreendedorismo, termo e prática que tem se tornado cada vez mais comum em nosso cotidiano, apresentado e incentivado pela lógica neoliberal como uma ação positiva do sujeito frente a períodos e situações de crise, é o tema do trabalho de Luana Jéssica Oliveira CARMO, que analisa a história de vida e a trajetória de um empreendedor à luz da ergologia. $\mathrm{O}$ trabalho de Carmo, fruto de sua dissertação de mestrado, traz à tona o fato de que o discurso de valorização do empreendedorismo camufla conflitos existentes entre capital e trabalho, assim como questões de desemprego estrutural e o papel do mercado nesse processo, desmistificando o discurso capitalista de sucesso individual. Ao tratar da atividade do empreendedor através da história de vida, a autora nos possibilita verificar como essa metodologia permite ao sujeito, refletir sobre sua prática e produzir conhecimentos sobre a atividade que exerce. Por fim, Carmo aponta o empreendedorismo enquanto uma ideologia que distorce a realidade.

Gleice Aparecida Santos SILVA apresenta os resultados encontrados em sua pesquisa de mestrado a partir do pensamento do filósofo e médico Georges Canguilhem e os conceitos elaborados por este acerca da saúde e da doença. Embasada na perspectiva da ergologia, a autora investigou os desafios relacionados à readaptação funcional de professores. A pesquisa, que teve como território o município de Belo Horizonte/MG, utilizou como instrumento entrevistas semiestruturadas, realizadas com cinco educadores em situação de readaptação. Para além dos desafios que a readaptação traz para os professores, a pesquisa demonstra como esses reinventam suas vidas frente à nova condição. O trabalho de SILVA torna-se ainda mais relevante quando consideramos o crescente número de adoecimento entre os professores, em especial, os da rede pública de ensino.

Com um título que já nos convida à reflexão: Fim de jogo? A transição de carreira de exatletas e o exercício da função gerencial, o texto de Amanda Fontes SILVA traz os resultados de um estudo realizado pela autora, cuja temática ainda é incipiente no campo da literatura da área. Amanda buscou compreender a influência da carreira esportiva no desempenho da função gerencial a partir da percepção de ex-atletas. Elegendo carreira, transição de carreira e função gerencial como categorias centrais, a autora analisa a transição de carreira do atleta para a função gerencial e a as peculiaridades da profissão. A pesquisa, de caráter qualitativo e descritivo, utilizou-se de entrevistas semiestruturadas como instrumento e entrevistou seis ex-atletas profissionais que desempenharam a função de gestor. A partir da metodologia de análise de conteúdo proposta por Bardin (1977), foi possível constatar fatores-chave que atuaram como determinantes para a construção da nova carreira.

Boa leitura!

Rodrigo Moreno Marques ${ }^{4}$

\footnotetext{
${ }^{4}$ Doutor em Ciência da Informação pela Escola de Ciência da Informação da Universidade Federal de Minas Gerais (UFMG). Professor do Departamento de Teoria e Gestão da Informação na Escola de Ciência da 
Neusa Pereira de Assis ${ }^{5}$

Uyara de Salles Gomide 6

\section{REFERÊNCIAS}

BC (BANCO CENTRAL). Relatório de Mercado Focus, publicado em 22 de maio de 2020. Brasília: Banco Central, 2020.

BRAMAN, Sandra. Change of State - Information, Policy and Power, London: MIT, 2006.

MBEMBE, Achille. Necropolítica. 3. ed. São Paulo: N-1 edições, 2018.

FMI (FUNDO MONETÁRIO INTERNACIONAL). World Economic Outlook Reports: the great lockdown. Washington: FMI, 2020.

Informação da UFMG. Pós-doutor pela University of London (Reino Unido) e pela Faculdade de Educação (FaE) da UFMG. E-mail: rodrigomorenomarques@yahoo.com.br.

5 Doutoranda no Programa de Pós-graduação em Educação: Conhecimento e Inclusão Social pela Universidade Federal de Minas Gerais (FaE/UFMG), Mestra em Educação pelo Centro de Educação Tecnológica (CEFET/MG), Graduada em História pela Universidade de Sete Lagoas, Pesquisadora do Grupo de Estudos e Pesquisa Marx, Trabalho e Educação (GEPMTE/UFMG), Professora da Rede Pública de Ensino, Membro da Organização Social Luta Pelo Social e Militante do Movimento Negro. E-mail: neusapassis@gmail.com.

6 Doutoranda no Programa de Pós-graduação em Educação: Conhecimento e Inclusão Social pela Universidade Federal de Minas Gerais (FaE/UFMG), Mestra em Economia pela Universidade Federal do Ceará (CAEN/UFC), Graduada em Ciências Econômicas pela Universidade Federal de Viçosa (DEE/UFV). Pesquisadora do Observatório Nacional do Sistema Prisional (ONASP/UFMG). E-mail: uyara.salles@gmail.com. 